\title{
Peningkatan Keterampilan Bahasa Inggris untuk Hiburan melalui Modul Pembelajaran Teks Narrative Berbentuk Fabel
}

\author{
Tri Wahyuningsih \\ SMA Muhammadiyah 1 Taman \\ brilliantsany2017@gmail.com
}

\begin{abstract}
The need for interactive and meaningful distance learning in English lessons is needed to improve students English skills including language skills and formative test-taking skills. This is done by the author through the use of interesting modules or for entertainment for students by utilizing narrative text material in the form of fables. The research method used is descriptive research on 32 students of class XI IPA 2 as a sample of research conducted at SMA Mubammadiyah 1 Taman. The results obtained in the form of observations of the achievement of English language skills including pronunciation, grammar, vocabulary, fluency, understanding are included in the intermediate or intermediate category with an average score of 2, 05. In addition, the students' English skills were also seen from the learning outcomes test data where the percentage of success of students who scored above the KKM (75) was 87.5\%, namely 28 students while those who scored below the KKM were 4 students. The conclusion of this study is the achievement of students' English skills after using the narrative text learning module in the form of fables is included in the medium or intermediate category/level 2+ and the percentage of success of formative tests above the KKM is $87.5 \%$.
\end{abstract}

Keywords: English Skills, Narrative Text Module, Fable

\begin{abstract}
Abstrak : Kebutuhan pembelajaran jarak jauh yang interaktif dan bermakna pada pelajaran bahasa inggris diperlukan untuk meningkatkan keterampilan bahasa inggris siswa meliputi keterampilan berbahasa dan keterampilan pengerjaan tes formatif. Hal tersebut dilakukan penulis melalui pemanfaatan modul yang menarik atau untuk hiburan bagi peserta didik dengan memanfaatkan materi teks narrative berbentuk fabel. Metode penelitian yang digunakan adalah penelitian deskriptif pada 32 siswa kelas XI IPA 2 sebagai sampel penelitian yang dilakukan di SMA Muhammadiyah 1 Taman. Hasil penelitian yang didapatkan berupa observasi ketercapaian keterampilan berbahsa inggris meliputi pelafalan (pronunciation), tata bahasa (grammar), kosa kata (vocabulary), kelancaran (fluency), pemahaman (comprehension) termasuk dalam kategori menengah atau intermediet dengan skor rata-rata 2,05. Selain itu keterampilan bahasa inggris peserta didik juga dilihat dari data tes hasil belajar dimana persentase keberhasilan siswa yang mendapatkan nilai di atas kkm (75) adalah sebanyak 87,5 $\%$ yaitu sebanyak 28 siswa sedangkan yang mendapatkan nilai di bawah $\mathrm{kkm}$ terdapat 4 siswa. Kesimpulan penelitian ini adalah ketercapaian keterampilan berbahasa inggris siswa setelah menggunakan modul pembelajaran teks narrative berbentuk fabel termasuk kategori menengah atau intermediet/level $2+$ serta persentase keberhasilan tes formatif di atas KKM sebesar $87,5 \%$.
\end{abstract}

Kata Kunci : Keterampilan Bahasa Inggris, Modul Teks Narrative

MANAZHIM : Jurnal Manajemen dan Ilmu Pendidikan

Volume 3, Nomor 2, Agustus 2021; 263-272

https:// ejournal.stitpn.ac.id/index.php/manazhim 


\section{PENDAHULUAN}

Pembelajaran jarak jauh menjadi sebuah kebiasaan baru yang harus dipaksakan untuk dilakukan menghadapi situasi pandemi yang belum juga mereda saat ini. Hal tersebut sesuai dengan surat keputusan bersama (SKB) 4 menteri, akan tetapi perubahan tersebut menimbulkan tantangan bagi para guru agar mampu mengelola kelas virtual menjadi kelas yang efektif ${ }^{1}$. Berdasarkan panduan pembelajaran jarak jauh bagi guru di masa pandemi yang dikeluarkan oleh kemendikbud, peran penting guru adalah membantu siswa menghadapi ketidakpastian yang disebabkan oleh pandemi serta melibatkan siswa untuk terus belajar meskipun kegiatan sekolah normal terganggu ${ }^{2}$.

Melihat pentingnya peran guru dalam pembelajaran di masa pandemi perlu adanya inovasi dalam melakukan pembelajaran yang menarik dan menyenangkan serta efektif untuk melatihkan keterampilan hidup bagi peserta $\operatorname{didik}^{3}$. Salah satu keterampilan yang dibutuhkan oleh peserta didik di di zaman modern ini adalah keterampilan dalam berbahasa inggris yang menjadi bahasa internasional. Sebagaimana dijelaskan oleh Hikmasari ${ }^{4}$ dalam penelitiannya bahwa saat ini banyak masyarakat yang mulai menyadari pentingnya kemampuan berbahasa Inggris baik dalam konteks teks maupun literasi lisan dalam dunia kerja maupun keperluan melanjutkan pendidikan ke luar negeri.

Penguasaan keterampilan bahasa inggris serta pembentukan karakter tentu bukan hal yang mudah diterapkan ${ }^{5}$. Oleh karena itu seorang guru haruslah cermat dan pandai memilih media pembelajaran sehingga mendukung proses belajar mengajar

${ }^{1}$ Mashuri, M., \& Hasanah, E. (2021). Manajemen Pembelajaran Bahasa Inggris dalam Meningkatkan Hasil Belajar Siswa saat Pandemi Covid-19 di SMA Muhammadiyah 3 Yogyakarta. Diglosia: Jurnal Kajian Bahasa, Sastra, Dan Pengajarannya, 4(2), 227-234. https://doi.org/10.30872/diglosia.v4i2.174

2 Kemdikbud. (2020). Panduan Pembelajaran Jarak Jauh. Kementrian Pendidikan Dan Kebudayaan, 28. https://bersamahadapikorona.kemdikbud.go.id/panduan-pembelajaran-jarak-jauh

3 Priyanto, A. (2020). Efektifitas Pembelajaran Daring Dalam Kegiatan Belajar Dan Mengajar Untuk Mencapai Tujuan Keterampilan Abad 21. Https://Bdkjakarta.Kemenag.Go.Id/. https://bdkjakarta.kemenag.go.id/berita/efektifitas-pembelajaran-daring-dalam-kegiatan-belajardan-mengajar-untuk-mencapai-tujuan-keterampilan-abad-21

Ad Http://journal.unair.ac.id/download-fullpapers-jurnal skripsi Inoko Hikmasari.pdf

${ }^{5}$ Ciptaning, D. Y. (2016). Peningkatan Keterampilan Menulis Narrativedalam Mata Pelajaran Bahasa Inggris Melalui Implementasi Media Audio Visual Pada Siswa Kelas X Di Sma Dwijendra. RETORIKA: Jurnal Ilmu Bahasa, 2(1), 161-177. https://doi.org/10.22225/jr.2.1.201.157-173 
yang sesuai keadaan dan kebutuhan siswa. Dalam penelitian ini penulisz berupaya untuk meningkatkan keterampilan bahasa inggris melalui pemanfaatan modul yang menarik atau untuk hiburan bagi peserta didik dengan memanfaatkan materi teks narrative berbentuk fabel.

\section{METODE}

Metode penelitian yang digunakan dalam penelitian ini adalah deskriptif yang dilakukan di SMA Muhamamdiyah 1 Taman. Salah satu SMA swasta islam yang ada di daerah perbatasan anatara sidoarjo dan surabaya. Populasi penelitian ini adalah siswa kelas XI sebanyak 210 siswa yang mana diambil sampel penelitian 32 siswa kelas X IPA 2 yang terdiri dari 16 siswa laki-laki dan 16 siswa perempuan.

Teknik pengumpulan data yang digunakan adalah trianggulasi data meliputi observasi, dokumentasi dan tes formatif pada peserta didik. Penelitian dilakukan selama bulan Juli di masa awal pelaksanaan tahun ajaran baru tahun 2021/2022. Sumber data yang digunakan dalam penelitian ini aalah sumber data primer dimana penulis melakukan penelitian secara langsung.

Instrumen pengumpulan data yang digunakan meliputi lembar observasi dan lembar tes hasil belajar peserta didik. Lembar observasi yang digunakan berupa pertanyaan atau pernyataan yang berhubungan dengan yang akan diteliti dan diamati secara langsung oleh guru 6 . Data observasi siswa untuk mengetahui keterampilan bahasa inggris peserta didik meliputi kemampuan berbicara bahasa inggris seperti pedoman pada Tabel 1 .

${ }^{6}$ Riduwan. (2013). Skala Pengukuran Vaiabel-variabel Penelitian. Alfabeta. 
Tabel 1. Penilaian Keterampilan berbicara bahasa Inggris ${ }^{7}$

\begin{tabular}{|c|c|c|c|}
\hline No & $\begin{array}{l}\text { Aspek yang } \\
\text { dinilai }\end{array}$ & Kriteria & Skor \\
\hline \multirow{4}{*}{1} & \multirow{4}{*}{$\begin{array}{l}\text { Pelafalan } \\
\text { (pronunciation) }\end{array}$} & $\begin{array}{l}\text { Hampir sempurna, Ada beberapa kesalahan, tetapi } \\
\text { tidak mengganggu makna }\end{array}$ & 3 \\
\hline & & Ada beberapa kesalahan dan mengganggu makna & 2 \\
\hline & & Banyak kesalahandan mengganggu makna & 1 \\
\hline & & Terlalu banyak kesalahan dan mengganggu makna & 0 \\
\hline \multirow{4}{*}{2} & \multirow{4}{*}{$\begin{array}{l}\text { Tata Bahasa } \\
\text { (grammar) }\end{array}$} & $\begin{array}{l}\text { Hampir sempurna, Ada beberapa kesalahan, tetapi } \\
\text { tidak mengganggu makna }\end{array}$ & 3 \\
\hline & & Ada beberapa kesalahan dan mengganggu makna & 2 \\
\hline & & Banyak kesalahandan mengganggu makna & 1 \\
\hline & & Terlalu banyak kesalahan dan mengganggu makna & 0 \\
\hline \multirow{4}{*}{3} & \multirow{4}{*}{$\begin{array}{l}\text { Kosa kata } \\
\text { (vocabulary) }\end{array}$} & Tepat/Sangat tepat & 3 \\
\hline & & Cukup tepat & 2 \\
\hline & & Kurang tepat & 1 \\
\hline & & Tidak tepat & 0 \\
\hline \multirow{4}{*}{4} & \multirow{4}{*}{$\begin{array}{l}\text { Kelancaran } \\
\text { (fluency) }\end{array}$} & Lancar/Sangat lancar & 3 \\
\hline & & Cukup lancar & 2 \\
\hline & & Kurang lancar & 1 \\
\hline & & Tidak lancar & 0 \\
\hline \multirow{4}{*}{5} & \multirow{4}{*}{$\begin{array}{l}\text { Pemahaman } \\
\text { (comprehension) }\end{array}$} & Faham/Sangat faham & 3 \\
\hline & & Cukup faham & 2 \\
\hline & & Kurang faham & 1 \\
\hline & & Tidak faham & 0 \\
\hline
\end{tabular}

Selain berupa tugas yang di observasi, penulis juga menggunakan metode tes tertulis untuk melihat hasil belajar siswa pada materi teks narative berbentuk fabel.

${ }^{7}$ Kurniawan, H., \& Ikhsan, A. (2021). Upaya Meningkatkan Kemampuan Berbicara \& Hasil Belajar Bahasa Inggris Melalui Penerapan Teknik Drill Pada Siswa Kelas XII MIPA2 SMA Negeri 1 Piyungan. Jurnal Ilmiah Universitas Muhammadiyah Buton, variable X, 71-84. 
Data hasil tes merupakan data mentah yang diperoleh pada setiap siklus melalui alar tes, kemudian diberi skor untuk setiap item. Tes berupa pilihan ganda yang merupakan tes formatif terdiri dari 10 soal pilihan ganda dengan masing-masing soal mendapat skor 10 .

\section{HASIL DAN PEMBAHASAN}

Modul pembelajaran bahasa inggris yang digunakan dalam penelitian ini membahas tentang materi teks narrative berbentuk fabel sederhana yang memiliki banyak makna dalam cerita teks narrative ataupun gambar-gambar ilustrasi. Indeks pencapaian kompetensi yang diharapkan dengan pemanfaatan modul yang dikembangkan adalah untuk memahami fungsi sosial memahami unsur kebahasaan serta memahami struktur teks narrative berbentuk fabel sederhana melalui pengalian informasi secara rinci baik secara lisan maupun tulisan. Hal tersebut disesuaikan dengan kompetensi dasar yang perlu dilatihkan kepada siswa menurut Permendikbud RI Nomor 37 tahun $2018^{8}$.

Berdasarkan hasil observasi di lapangan terkait peningkatan keterampilan bahasa inggris pada materi teks narrative berbentuk fabel terlihat bahwa keterampilan berbicara bahasa inggris dari sampel penelitian yang dilakukan di kelas X IPA 2 SMA Muhamamdiyah 1 Taman termasuk dalam level 2 atau kategori menengah (intermediet) sehingga bisa dikatakan cukup baik dan bisa memahami teks narative berbentuk fabel (dapat dilihat pada tabel 2).

Tabel 2. Lembar Observasi Keterampilan Berbicara Bahasa Inggris

\begin{tabular}{ccc}
\hline No & Aspek yang dinilai & Skor \\
\hline 1 & Pelafalan (pronunciation) & 1,75 \\
\hline 2 & Tata Bahasa (grammar) & 2,25 \\
\hline 3 & Kosa kata (vocabulary) & 2,00 \\
\hline
\end{tabular}

8 Permendikbud. (2018). Permendikbud RI Nomor 37 tahun 2018 tentang Perubahan atas Peraturan Menteri Pendidikan dan Kebudayaan Nomor 24 tahun 2016 tentang Kompetensi Inti dan Kompetensi Dasar Pelajaran pada Kurikulum 2013 pada Pendidikan Dasar dan Pendidikan Menengah. JDIH Kemendikbud, 2025, 1-527. 


\begin{tabular}{llc}
\hline 4 & Kelancaran (fluency) & 1,75 \\
\hline $5 \quad$ Pemahaman (comprehension) & 2,5 \\
\hline \multicolumn{2}{c}{ Skor rata-rata } & 2,05 \\
\hline Kriteria ketercapaian skor: & \\
Cukup Aktif = Level 2+ atau Menengah (intermediate) & \\
Cukup Aktif = Level 3/Lanjut (Advanced) &
\end{tabular}

Keterampilan dalam berbicara merupakan sebuah keterampilan dalam berkomunikasi baik berupa penyampaian pendapat atau pengutaraan apa yang sedang dipikirkan. Keterampilan berbicara merupakan sebuah indikator terpenting dalam membangun komunikasi yang baik ${ }^{9}$. Proses pembelajaran yang baik akan menghaslikan pola komunikasi yang baik terutama dalam pembelajaran bahasa Inggris di mana merupakan bahasa yang diakui oleh banyak negara sebagai bahasa internasional. Pentingnya bahasa Inggris bukan hanya dalam berapa banyak orang yang berbicara tetapi untuk apa itu digunakan seperti bahasa utama berita dan informasi di dunia, bahasa bisnis dan pemerintahan, serta bahasa komunikasi maritim dan kontrol lalu lintas udara internasional. Bahasa inggris menjadi bahasa yang lebih banyak digunakan dalam berbagai sektor di beberapa negara bukan bahasa asli dari negara asalnya ${ }^{10}$.

Pembelajaran menggunakan cerita rakyat dengan berbagai teks dan illustrasi yang telah disiapkan dalam modul beperan penting dalam meningkatkan memorization bagi peserta didik serta membuat pembelajaran lebih menarik. Memorization sendiri memiliki peran yang penting dalam keterampilan berbicara bahasa Inggris, hal ini disebabkan berbicara merupakan kemampuan yang mengharusnya setiap orang untuk

\footnotetext{
${ }^{9}$ Kholid, M. F. N., Yufrizal, H., \& Raja, P. (2014). Improving Students' Speaking Ability Through Drill Technique. 3(1), 1-13.

${ }^{10}$ Kusuma, C. S. D. (2018). Integrasi Bahasa Inggris dalam Proses Pembelajaran (Chusnu Syarifa Diah Kusuma) integrasi bahasa inggris dalam proses pembelajaran. Jurnal Efisiensi-Kajian Ilmu Administrasi Edisi Agustus, XV(2), 43-50. 
berinteraksi dengan orang lain yang melibatkan pengetahuan ataupun keterampilan linguistik ${ }^{11}$.

Selain itu keterampilan bahasa inggris peserta didik juga dilihat dari data tes hasil belajar dimana persentase keberhasilan siswa yang mendapatkan nilai di atas kkm (75) adalah sebanyak 87,5\% yaitu sebanyak 28 siswa sedangkan yang mendapatkan nilai di bawah kkm terdapat 4 siswa sebagaimana dapat dilihat pada tabel 3 .

Tabel 3. Data hasil pengerjaan tes formatif peserta didik

\begin{tabular}{clc}
\hline No & \multicolumn{1}{c}{ Aspek yang dinilai } & Skor \\
\hline 1 & Jumlah Siswa (sampel penelitian) & 32 \\
\hline 2 & Di bawah KKM $(<75)$ & 4 \\
\hline 3 & Di atas KKM $(>75)$ & 28 \\
\hline 4 & Nilai Rata-Rata & 85 \\
\hline 5 & Persentase Keberhasilan & $87,5 \%$ \\
\hline
\end{tabular}

Kriteria

Berhasil

Evaluasi atau penilaian merupakan aspek pembelajaran yang paling kompleks, karena melibatkan banyak latar belakang dan hubungan, serta variabel lain yang mempunyai arti apabila berhubungan dengan konteks yang hampir tidak mungkin dapat dipisahkan dengan setiap segi penilaian ${ }^{12}$. Berdasarkan penelitian yang telah dilakukan dapat dilihat bahwa modul teks narrative berbentuk fabel yang dikembangkan oleh penulis berhasil untuk meningkatkan keterampilan bahasa inggris peserta didik baik dalam keterampilan berbicara maupun pengerjaan tes tertulis.

11 Hanafiah, W. (2019). Peningkatan Keterampilan Berbicara Bahasa Inggris Melalui Media Film. Epigram, 16(2), 149-159. Https://Doi.Org/10.36733/Jsp.V1i1.463

12 Mashuri, M., \& Hasanah, E. (2021). Manajemen Pembelajaran Bahasa Inggris dalam Meningkatkan Hasil Belajar Siswa saat Pandemi Covid-19 di SMA Muhammadiyah 3 Yogyakarta. Diglosia: Jurnal Kajian Bahasa, Sastra, Dan Pengajarannya, 4(2), 227-234. https://doi.org/10.30872/diglosia.v4i2.174 


\section{KESIMPULAN}

Modul pembelajaran teks narrative berbentuk fabel dapat digunakan sebagai media pembelajaran yang efektif untuk meningkatkan keterampilan bahasa inggris sekaligus hiburan bagi siswa. Hal tersebut dapat dilihat dari ketercapaian keterampilan berbahasa inggris siswa pada kategori menengah atau intermediet/level $2+$ serta persentase keberhasilan tes formatif di atas KKM sebesar 87,5\%.

\section{DAFTAR PUSTAKA}

Ciptaning, D. Y. (2016). Peningkatan Keterampilan Menulis Narrativedalam Mata Pelajaran Bahasa Inggris Melalui Implementasi Media Audio Visual Pada Siswa Kelas X Di Sma Dwijendra. RETORIKA: Jurnal Ilmu Bahasa, 2(1), 161-177. https://doi.org/10.22225/jr.2.1.201.157-173

Hanafiah, W. (2019). Peningkatan Keterampilan Berbicara Bahasa Inggris Melalui Media Film. Epigram, 16(2), 149-159. Https://Doi.Org/10.36733/Jsp.V1i1.463

Hikmasari, I. (2015). Pemahaman Berbahasa Inggris Oleb Siswa Kampung Inggris. 14. Http://journal.unair.ac.id/download-fullpapers-jurnal skripsi Inoko Hikmasari.pdf

Kemdikbud. (2020). Panduan Pembelajaran Jarak Jauh. Kementrian Pendidikan Dan Kebudayaan, 28. https://bersamahadapikorona.kemdikbud.go.id/panduanpembelajaran-jarak-jauh/

Kholid, M. F. N., Yufrizal, H., \& Raja, P. (2014). Improving Students' Speaking Ability Through Drill Technique. 3(1), 1-13.

Kurniawan, H., \& Ikhsan, A. (2021). Upaya Meningkatkan Kemampuan Berbicara \& Hasil Belajar Bahasa Inggris Melalui Penerapan Teknik Drill Pada Siswa Kelas XII MIPA2 SMA Negeri 1 Piyungan. Jurnal Ilmiah Universitas Mubammadiyah Buton, variable $X, 71-84$.

Kusuma, C. S. D. (2018). Integrasi Bahasa Inggris dalam Proses Pembelajaran (Chusnu Syarifa Diah Kusuma) INTEGRASI BAHASA INGGRIS DALAM PROSES PEMBELAJARAN. Jurnal Efisiensi-Kajian Ilmu Administrasi Edisi Agustus, XV(2), 43-50.

Mashuri, M., \& Hasanah, E. (2021). Manajemen Pembelajaran Bahasa Inggris dalam Meningkatkan Hasil Belajar Siswa saat Pandemi Covid-19 di SMA Muhammadiyah 3 Yogyakarta. Diglosia: Jurnal Kajian Bahasa, Sastra, Dan Pengajarannya, 4(2), 227-234. https://doi.org/10.30872/diglosia.v4i2.174

Permendikbud. (2018). Permendikbud RI Nomor 37 tahun 2018 tentang Perubahan atas Peraturan Menteri Pendidikan dan Kebudayaan Nomor 24 tahun 2016 tentang Kompetensi Inti dan Kompetensi Dasar Pelajaran pada Kurikulum 2013 pada Pendidikan Dasar dan Pendidikan Menengah. JDIH Kemendikbud, 2025, 1527. 
Tri Wahyuningsih

Priyanto, A. (2020). Efektifitas Pembelajaran Daring Dalam Kegiatan Belajar Dan Mengajar Untuk Mencapai Tujuan Keterampilan Abad 21. Https://Bdkjakarta.Kemenag.Go.Id/.

https://bdkjakarta.kemenag.go.id/berita/efektifitas-pembelajaran-daring-dalamkegiatan-belajar-dan-mengajar-untuk-mencapai-tujuan-keterampilan-abad-21

Riduwan. (2013). Skala Pengukuran V aiabel-variabel Penelitian. Alfabeta. 